\title{
A Reactive Behavior Agent: Including Emotions into a Video Game
}

\author{
A. L. Laureano-Cruces ${ }^{\star 1,2,3}$, D. A. Acevedo-Moreno ${ }^{3}$, M. Mora-Torres ${ }^{3}$, J. Ramírez-Rodríguez ${ }^{1,2}$ \\ ${ }^{1}$ Departamento de Sistemas, Universidad Autónoma Metropolitana \\ Azcapotzalco, San Pablo 180, 02200 México D.F., México \\ * clc@correo.azc.uam.mx \\ ${ }^{2}$ Laboratoire Informatique d'Avignon / Université d'Avignon et des \\ Pays de Vaucluse, BP 91228, 84911 Avignon Cedex 9, France \\ ${ }^{3}$ Posgrado en Ciencia e Ingeniería de la Computación - Universidad \\ Nacional Autónoma de México, Edificio anexo al IIMAS, \\ 3er. Piso, Circuito Interior, Ciudad Universitaria Coyoacán CP04510, \\ México D.F., México
}

\begin{abstract}
Why we have emotions and how they influence human behavior are two questions we constantly ask ourselves. According to researchers in the field, there are two kinds of information that the person receives to make a decision. This information is integrated to generate a whole. One comes from ourselves it is proprioceptive and refers to emotions; the other one is external, it comes from the environment. Thus, emotions are immersed in different areas of a person's life, including social, functional, and cognitive aspects. It has an important role in the decision-making process. It is on this last point that this paper focuses its approach, which consists of including a cognitive structure of emotions in a reactive behavior in order to enrich behavior, including the information generated through internal evaluation of the external physical stimuli. Our work is based on the OcC theory (named after the name of its authors: Ortony, Collins and Clore). This theory proposes that a decision-making process is affected through different perspectives: a) goals and events, b) agents and their actions, and c) objects and their capacity for attraction. The case study is situated within a scenario that represents an approach that seeks to include a module of emotions within the design of the architecture of a videogame.
\end{abstract}

Keywords: cognitive structure of emotions, decision-making process, reactive behaviors, affective computing.

\section{RESUMEN}

Por qué tenemos emociones y cómo influyen en el comportamiento humano son dos preguntas que constantemente nos hacemos. De acuerdo con investigadores en el campo, se trata de dos tipos de información que la persona recibe para tomar una decisión. Esta información se integra para generar un todo. La información que viene de nosotros mismos es la propiocepción y se refiere a las emociones; la otra es externa y proviene del medio ambiente. Así, las emociones están inmersas en diferentes áreas de la vida de una persona, incluidos los aspectos sociales, funcionales y cognitivos. Tienen un papel importante en la toma de decisiones. Es en este último punto que el trabajo centra su enfoque, que consiste en incluir una estructura cognitiva de las emociones en un comportamiento reactivo a fin de enriquecer el comportamiento, incluyendo la información generada a través de la evaluación interna de los estímulos físicos externos. Nuestro trabajo se basa en la Teoría OCC (por el nombre de sus autores: Ortony, Collins y Clore). Esta teoría propone que la toma de decisiones se ve afectada a través de perspectivas diferentes: a) las metas y los acontecimientos, b) los agentes y sus acciones, y c) los objetos y su capacidad de atracción. El caso de estudio se encuentra dentro de un escenario que representa un enfoque que trata de incluir un módulo de las emociones en el diseño de la arquitectura de un videojuego.

\section{Introduction}

\subsection{Reactive behaviors}

In the 1980s the design of reactive behaviors experienced a boom, producing interesting results in different applications [9, 10]. According to Brooks [5], one of the most important points is reaction speed in systems because of parallel processing of information through the different levels of abstraction that make up encapsulated behavior in agents. 
A reactive behavior is an emerging behavior, and therefore is endowed with an adaptive capacity based on the state of the physical stimuli coming from the environment at a given moment in time within a context. When we model such behaviors, it is essential to know these physical stimuli, which appear constantly in a dynamic environment, and trigger the different actions, which in turn configure the universe of behaviors [12]. In this type of behaviors, the control of action-selection lies in the analysis and design, and for that reason the latter constitutes an important point of departure.

This means that the designers of reactive behaviors need to invest considerable time in the design to leave the action-selection mechanism precompiled or hardwired [27]; and that leads us to the following conclusion: when we use planning mechanisms, a lot of deliberative work is left to the system, whereas the reactive approach leaves a lot of deliberative work to the designer. This leads to the emergence of varied methodologies seeking to design and encapsulate such reactive behaviors in agents, [9, 11, 17, 33, 34].

In these systems, the internal modeling of the system is based on the behavior the designer wants the system to display; therefore, we need a methodology that gives us a clear and complete idea of what we want, with the latter in mind we can in turn define partial objectives based on the behaviors that we will then encapsulate in the agents' behavior $[6,11,13,17,33,34]$.

In the case study, we utilize the term agent and character in the same fashion. Last because an agent will be represented in the videogame by a character and also it is an agent with its encapsulated behavior.

\subsection{Emotions}

It was not until the late 1990s that a new branch of research related to emotions ${ }^{1}$ and called affective computing (AC) emerged [26, 32]. This marked the time when emotions acquired importance as part

\footnotetext{
${ }^{1}$ In the text we will refer to emotions as a synonym for affections, and affections are a cognitive representation of emotions.
}

of various aspects of behavior, among them the decision making process [22].

Because emotions are a crucially important aspect of human behavior, the idea of including, in addition to the physical stimuli received from the dynamic environment; a cognitive structure of emotions derived from an internal interpretation of that same environment is an appealing one. This will be represented by an abstraction that will be the sum of events that will combine to form an emerging behavior [3, 14, 19].

The focus of this work is the analysis and design of an affective structure taking into account two of the aspects of the OCC theory; that decision was because the third aspect could be considered in the others. In this way, we construct an emotional assessment macrostructure of emotions based on 1) events, which take into account the goals and their consequences; and 2) the emotions based on the attribution, which take into account the plausibility of the action from an agent. Last for each behavior that we are going to represent. In this way we design a reactive behavior taking into account two information sources: 1) the affective that is intrinsic, and come from an internal vision of the world; and 2) the physical environment. This kind of emotional assessment macrostructure has been used successfully to model the decisionmaking process of a tutor module as part of an intelligent learning system $[15,16,21]$. Also, it has been utilized to model the following: the synthetic emotions of a virtual pet [18], a cognitive model for the Red Baron [19], and in a maze videogame that attempts to adapt itself to the emotional state of the user in a maze game [20].

In this context, our work is ordered as follows: Section 2 contains an explanation of the importance of emotions. In Section 3, we describe the components of emotive architecture and explain its function. In Section 4, we design the emotive architecture and explain the behaviors and emotions based on the theoretical framework of the OCC theory. In Section 5, we explain the emotional assessment macrostructure and their implications when it is related to goals and norms as part of the information generated by the events in the environment and which have a final representation in the behavior. In Section 6, we 
show some scenarios product of the videogame and related with the emotional assessment macrostructure. Finally, in Section 7, we present our conclusions and future work.

\section{Emotions and their relationship with behavior}

Each day of our lives we are faced with different tasks and challenges, some everyday and simple, others complex and very important, for example the selection of shoes that we will be wearing today, food preparation, organization of activities we will have during the week or perhaps a workrelated decision on which our economic future depends. All these situations produce a large amount of activity in our brains; however, we rarely pause to think about these processes and we do not take into account that every aspect of the environment in conjunction with ourselves has implications. The concept of cognition is the faculty of human beings to process information from perception. The acquired knowledge and subjective characteristics allow assess and consider certain aspects at the expense of others.

With this in mind, we can consider that any problem requires contextualization and a certain amount of information that comes from collection and storage prior experience. This together with others factors help us in the decision-making process with a final action. Hence, we can say that cognition is a complex process that depends on many factors but it is certainly determinant of the behavior of each individual $[8,22,23]$.

Returning to the example of selecting a pair of shoes: suppose that a businessman was summoned to a meeting with important new investors, that morning while he prepares to leave home, he has to decide whether to wear a pair of comfortable shoes that he wears to work every day or another pair of shoes that he knows will cause him foot pain but look new and more elegant. Probably, in this context, that person will wear the most elegant shoes to make a good impression at the meeting. This simple example shows how a person takes information from his/her environment; in this case, the appearance of the shoes makes him recall some data about how that pair of shoes cause him discomfort in his feet, and on the other hand, he takes into consideration extra information that tells that appearance is important to make a good impression.

Now go one step further, suppose that the meeting was a success and the economic future of this person is ensured, then we could say that he is very happy about what happened. That same afternoon he realizes that his son has failed a subject at school, what could be his reaction? Before answering this question, we must analyze the opposite case in which the meeting was a complete failure and his company is at risk of bankruptcy, leaving this man with great frustration and inconvenience during the rest of day, then how does he respond to the news about his son? Clearly influenced by many factors, including the fact that this is not the first time that he punishes his son for the same reason, however, we could make the assumption that, in the first case, the parent might realize that he has not spent enough time with his son to support him, in which case he can opt for offering help to his son and show understanding, by contrast, in the situation where things have not gone well for him, the news about his son may be one more reason to increase his displeasure, thus without much thought, he could opt for punishing his son for not having revised enough for the exam.

With ease we can see that the previous situation does not only involve cognitive processes for decision making, but one aspect that influences these processes are the emotions experienced by the individual, in fact some research $[22,26,30$, 32] shows that cognition and emotions are not separate elements, however, both are crucial in human intelligence. Therefore, emotional states are not especially different from the process called thinking. Emotions are certain ways to think that we use to increase resourcefulness, and this variety of ways to think must be a substantial part of what we call intelligence [23].

From the perspective of artificial intelligence and given the affirmation that emotions affect our behavior, a promising avenue opens where we can see emotions as an essential piece in the techniques and algorithms, whether for the decision-making process, planning, or even a true simulation of human behavior [31]. This translates 
into reviewing and integrating more information to allow software systems to do their jobs and get more adaptable interfaces. On this point, it is important to emphasize that emotions do not completely shape the course of actions, but they do make a difference by influencing the decisionmaking process. In other words, they are another source of information to be considered. In the case study we focus on the cognitive aspect of emotions.

\subsection{What is an emotion?}

From the previous example we can conclude that emotions are present at all times, always changing and constantly motivating us to adapt to the situations and challenges we face.

According to [35], emotions are multidimensional, they are phenomena that can be observed and studied from different points of view: 1) subjective, 2) biological, 3) propositional and 4) social.

The subjective-cognitive dimension of emotion has a direct dependency on the interpretation of the event and is related with the mood. It refers to how they make us feel (cheerful or irritated), it is important to remark that it is a proprioceptive aspect. The biological dimension of emotion is related to the mobilization of energy that implies the adaptation capacity to any situation that arises. Emotions can be seen as agents of purpose, because they create a motivational urge. Finally, they have a social aspect dimension because they inform about the quality of personal interaction: they encourage formation of groups, motivate social sharing, among other things.

To understand or define emotion, we need to study each of the four dimensions and how they interact. In the human being they work in a parallel way to make a coordinate action possible. Table 1 offers a synthesis of these four dimensions.

Consequently, given its complexity, emotion proves difficult to be defined. According to [35], emotion is a psychological construct that unifies and coordinates the four aspects of experience in a synchronized pattern, resulting in a coherent reaction to a provocative situation.

\begin{tabular}{|c|c|c|}
\hline Dimension & $\begin{array}{l}\text { Contribution to } \\
\text { the Emotion }\end{array}$ & Manifestation \\
\hline $\begin{array}{l}\text { Subjective } \\
\text { (Cognitive) }\end{array}$ & $\begin{array}{l}\text { Feelings and } \\
\text { awareness }\end{array}$ & Self_reporting \\
\hline $\begin{array}{c}\text { Biological } \\
\text { (Physiological) }\end{array}$ & $\begin{array}{l}\text { Excitation, physical } \\
\text { preparation, motor } \\
\text { responses }\end{array}$ & $\begin{array}{c}\text { Brain circuits, } \\
\text { autonomous } \\
\text { nervous system, } \\
\text { endocrine } \\
\text { (hormonal) system }\end{array}$ \\
\hline $\begin{array}{c}\text { Functional } \\
\text { (Propositional) }\end{array}$ & $\begin{array}{l}\text { Goal oriented } \\
\text { motivation }\end{array}$ & $\begin{array}{l}\text { Urge to commit to } \\
\text { responses to face } \\
\text { the situation } \\
\text { appropriately }\end{array}$ \\
\hline $\begin{array}{l}\text { Expressive } \\
\text { (Social) }\end{array}$ & Communication & $\begin{array}{c}\text { Facial expressions, } \\
\text { body postures, } \\
\text { vocalization }\end{array}$ \\
\hline
\end{tabular}

Table 1. Dimensions of the emotion.

The last definition concurs with that cited in [7], taken from the Oxford English Dictionary, which describes emotion as any agitation and disturbance, feeling, passion; any vehement or excited mental state. In this definition the author emphasizes that emotion is a whole made up by 1 ) a feeling and its characteristic thoughts, 2) psychological and biological states, and 3) a variety of tendencies to act.

According to [23], it is difficult to define the word emotion in part because it is utilized to describe different things whose relationships we do not comprehend, and when a change of mental state is given, we utilize the same words. Trying to make it limited and simple we can think that emotions are certain ways to think that we use to increase resourcefulness. And this variety of ways to think must be a substantial part of what we call intelligence.

There are hundreds of emotions expressed through their combinations, variables, permutations, and nuances; thus, there are more subtleties than we can imagine.

Consequently, we understand that there are as many emotional profiles as people in the world and each of us bears imprinted a unique profile that we will call the dynamic emotional map, which is like a fingerprint, shaped by experiences, genetic data, learning, and culture, among other factors. 


\subsection{Study perspectives for emotions}

From the last section, it is clear that there are basically two approaches, the cognitive and the biological, and their point of departure for discussion is to answer the question of how emotions form. Recognizing that both approaches underlie emotion does not answer the question of which comes first.

In the case of the biological school of thought, its adherents: Carroll Izard, Paul Ekman, Jaak Panksepp, and Robert Zajonc, [35] argue that children respond emotionally despite their cognitive deficiencies which include vocabulary and limited capacity for recall. As a child grows, he or she learns language, acquires memory skills, and deploys cognitive processes. But even with the inclusion of the latter, they insist that the process of emotion generation is automatic and unconscious and is mediated by sub-cortical structures. In this vein, they argue that emotions emerge very rapidly, are short lived, and can occur automatically/unconsciously, and often one can react even before realizing what has happened (the limbic system).

According to Pankseep, [35], emotions arise from the genetically inherited neuronal circuits that regulate the brain's activity. In the case of the cognitive school of thought, its proponents are Richard Lazarus, Klaus Scherer, Bernard Weiner, and James Averril [35] They argue that cognitive activity is a necessary prerequisite for the presence of emotion. Lazarus argues that without an understanding of the personal relevance of the potential impact of an event on one's personal well being, there is no reason to respond emotionally. Scherer argues that people process information without the need to experience an emotion. Certain situations produce emotions, and others do not; it all depends on novelty, pleasure, meaning of goal/need, potential for confrontation, or compatibility of norm. These five types of assessment are what constitute the type of cognitive processing that gives rise to emotions. For Averill, emotions are understood best in a social or cultural context. In this case emotion is understood best as the response to events with social content, as in the case of anger: toward one who breaches a social norm or denies responsibility for an action.
Thus, it is clearly harder to study the nether reaches of brain circuits than to analyze feelings labeled verbally. However, both sides clearly establish their respective positions. From our point of view, both sides are entirely correct, and they both give meaning to the process of emotion. This position in turn gives rise to approaches like Buck's [35], which maintain that human beings have two synchronous systems that activate and regulate emotion.

In this case, there is an innate, spontaneous, physiological system that reacts unconsciously to emotional stimuli, and a second cognitive system, based on experience that reacts in an interpretative and social manner. The first type of reactions is related with the limbic system conformed by the hypothalamus, the hippocampus in the temporal lobe, and the amygdala. The second type of reactions is related with the cortex system (gray matter) above the last one. Therefore, the brain has two ways to react: one that is fast and noisy and another one which is slower and more accurate.

The physiological system of emotion first appeared in human evolution (the limbic system), and the cognitive system of emotion appeared later as social creatures became increasingly cerebral and sociable (neurocortex).

As is to be expected, these ideas open a vast terrain for implications and ideas that inspire the field of research in affective computing. At this point, it is important to stress that our research focus is on the cognitive structure of emotions and, accordingly, omits the biological dimension. If the expressions of emotions have an origin first neurological or cognitive is not of interest for the present work. Our point is how can emotions be generated in computers, recognized by computers, and expressed by computers? In other words what is the mapping that connects the emotion that you are cognitively or physically experiencing to the way in which it is expressed to others [32].

Our research was conducted using the OCC theory [28], which establishes a computer model for its treatment and application of a cognitive influence in emotions. Cognitive systems include both natural and artificial information processing systems responsible for perception, learning, reasoning, communication, action and more. One of the goals is to understand 
how natural and artificial processing devices could solve the most complex systems. A cognitive influence can be considered when it involves: appraisal, comparison, categorization, inference, attribution, or judgment [24].

One of the final goals of this work is that the final action takes into account the emotions. There are conditions that complicate this representation in the environment like the intensity of the emotion, social mores, the type of emotion, and how the state was induced. The inclusion of such conditions is part of the OCC theory, which offers a unique and contextindependent methodology, which in turn allows us to design specific environments, using global and local variables. The latter allow us to make assessments analyzing the environment from three different perspectives. Below, we present a brief explanation of the theory.

\subsection{The OCC Theory}

The OCC theory [28] proposes a general structure, which postulates the existence of three main classes of emotions, resulting from a focus on each of the three fundamental facets of the world (Figure 1):

- Events and their consequences

- Agents and their actions

- Pure and simple objects

For this purpose, it establishes as evaluation criteria:

- Goals to evaluate events.

- Norms to evaluate the action of agents.

- Attitudes to evaluate objects.

The three main classes of emotions postulated are

- Emotions based on events: goals related to events are specified.

- Attribution emotions: responsibility is attributed to agents for their actions as a function of norms.

- Attraction emotions: based on attitudes in relation to objects.

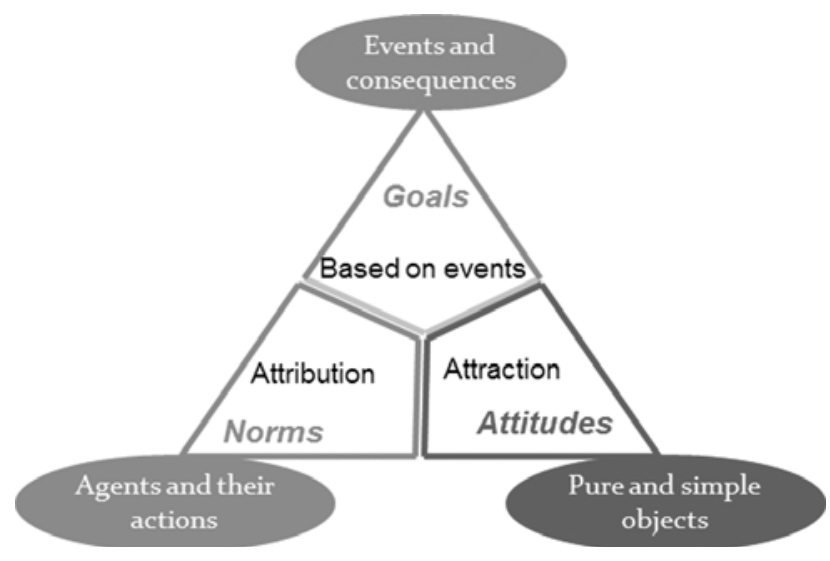

Figure 1. Proposed emotional structure $d$ escribed by the OCC theory.

The intensity of emotions can be affected by what are known as local variables (desirability, plausibility, and the ability to attract) and global variables (proximity, sense of reality, arousal, and unexpectedness). Thus, the cognitive representation of emotions is also modified.

Through these variables, we get the emotions linked to these classes of emotions in a specific context. The OCC theory proposes a hierarchical structure composed of a higher goal (general) and sub-goals called instrumental goals (more specific). These goals are related to each other with links defined as necessary, sufficient, facilitators, or inhibitors. The goals are of different kinds: 1) active persecution (AG); one wants them to get done, c) interest (IG); one wants them to happen, and e) filler (FG) that are cyclical, reason why even when they are done, they are not abandoned.

The case study considers: 1) events, which take into account the goals and their consequences, and 2) the emotions based on attribution, which take into account the plausibility of the action from an agent. The OCC theory gives a global variable to measure each kind of emotion. The first case has the disability like unit measure and the second, the norms. With this in mind, an emotive architecture is developed in the context of a videogame (Figure 2). 


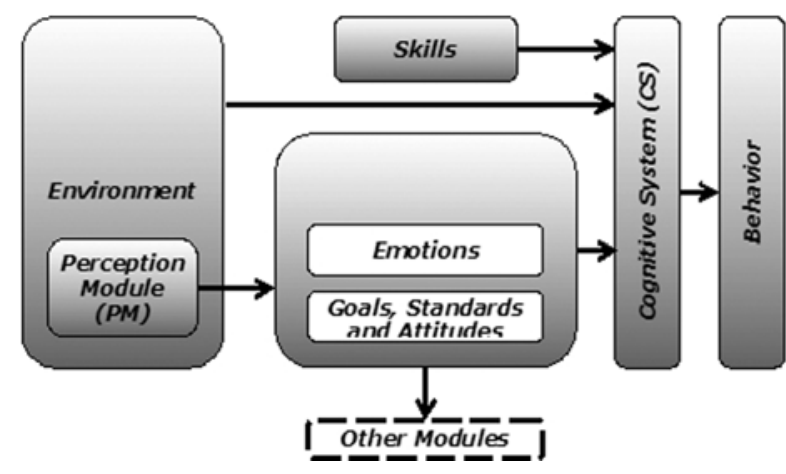

Figure 2. Emotive architecture.

\section{An emotive architecture}

Before introducing our proposal, it is necessary to define certain concepts that will help us to understand its functioning and which also represent some of the proposed modules that include the ideas described in the preceding section. For more details, see [1, 2, 15, 19, 25].

- Environment: as in a multi-agent system, the world where objects and agents are housed, the agents through their actions affect the environment in search of fulfilling their objectives [12].

- Signs: they are signs that use objects to communicate with each other, taking all the necessary information for processing. This is a basic and indispensable component on which message based systems function (is part of the agent communication language).

- Event: they are things that happen without necessarily requiring the intervention of an agent, for example when it starts to rain or a relation dies. The main feature in assessing an agent's emotional reaction to an event is its desirability. Thus, the death of a loved one is a highly undesirable event, whereas the recovery of a loved one after a prolonged illness is highly desirable. In the same sense it is referred in the OCC theory. It is a belief of what is happening in the environment. This includes also the result of actions taken by agents $[13,17,33,34]$.
- Perception module (PM): following the polling scheme, this object sees everything that happens within the environment. Its aim is to generate logical events that encapsulate an abstraction with information about the events relevant to the agents who are expected to experience emotions [37].

- Skills: within the context of videogame skills are represented by the capabilities of the character, with direct impact on their environment or to itself. For example: walking or shooting.

- Behavior: it is a well-defined set of skills that are completed in sequence for example: attacks, that may include skills such as walking, selecting a target and shooting. Usually, each behavior is generated with the objective of achieving a specific goal and due to frequent changes in the environment (dynamic) it is common for a behavior to remain incomplete.

- Affective Individual Module (AIM): this module defines an instance for each individual (in this case the agents) representing the emotions and their intensities according to their feelings as well as their goals, norms and attitudes. It is responsible for assessing: 1) the impact of events in the goals, and 2) the actions of agents based on the norms. Lastly, in order to diagnose the different emotions of the agent and it is part of the mechanisms that permit the readjust of its goals.

- Cognitive System (CS): it is responsible for making the information relevant and necessary to produce a behavior in the agent, it is the place where the decision-making process is performed. This component is common in any Al implementation contained in a videogame. Its implementations are varied [2, 3, 19], and the only change in relation to our design is that in this system relevant information for emotions can be obtained.

The agents' real behavior will be defined by the implementation of this cognitive system. Figure 2, shows the emotive architecture that represents the 
general concept of our proposal to be implemented in the design of the videogame.

In any virtual environment (the case study a videogame) there is a logical representation of the world where there are all the objects, and agents, together with their properties. This environment is constantly changing as the game unfolds. The PM constantly monitors the environment in search of changes that may be interpreted as important events for agent players, in this case, these events must be defined based on the characteristics and rules of the game. This module is the first idea related to the theoretical framework, as it identifies and groups the set of events that, according to the OCC model, will be submitted to the process of evaluation by each individual. The Affective Individual Module receives events perceived by the PM to conduct the assessment process of emotions based on the goals, rules and attitudes. This process generates a value of intensity for each emotion considered which, in the OCC model, will be necessary to determine if each individual emotion is active or not $[1,2$, $3,16]$. The next step in the system shows that the Cognitive System receives information from the skills module. With this information the agent, according to its capabilities, can know what can and what can not do to change the environment in order to get its goals [6]. In this case, it is necessary to emphasize that the CS has access to environment information (evidence) that enables it to see if the agent can perform any action under current conditions. Finally, the CS gets the emotions present in the AIM as well as the goals of the agent; integrating all the information in order to produce a coordinated behavior. The CS will carry out the resulting behavior until its end, while environmental conditions and AIM remain unchanged.

In relation to the modules, we need to clarify that AIM is unique module content in each agent. In the case of abilities (training) and tools (like the gun) they are alike but the emotions each agent feels have different intensity according to its dynamic emotive structure, and this is what makes the difference when different behaviors are generated in the CS of each agent.
Finally, we remark that any other module within the architecture of the game can get information about the emotions present in each agent so that an animation module can identify an emotion of anger affecting the character model (mesh, texture or image as the specific implementation of the video game) corresponding, to enable it express its emotion.

\section{Design of an emotive architecture following the OCC theory}

There are many areas where a videogame's level of credibility can be raised, for example: animation, the expressiveness of the characters, interaction with the environment, etc. This paper seeks to obtain this characteristic in the process of planning actions incorporating a model of emotions in reactive behavior, which will allow the agent to make decisions in a manner similar to how a human makes different decisions, in other words; including the emotions it experiences at a given time $[19,30]$.

\subsection{Environment}

In any virtual environment, a clear description of its characteristics is essential, not only to find the most appropriate implementation, but also to define all the elements and aspects with which agents will be able to interact in order to achieve their objectives.

For this project, we chose the context of a war videogame. Two groups of agents will try to eliminate one another. All the characters have the same group of basic actions, which include: move, shoot, punch, and pick up objects [38].

Below we describe certain features of the environment that will be useful to integrate a representative vector ${ }^{2}$ of the state of the virtual world at a given moment in a specific time for each of the agents. This vector is indispensable for the agent to be able to execute planning and thereby

\footnotetext{
${ }^{2}$ In the context of this paper, we define a vector as a group of variables that jointly represent the characteristics of an object at a given moment in time. Thus, each agent can contain a vector that contains the interpretation of particular object, with that interpretation based on his perception.
} 
choose the most suitable behavior, with the aim of achieving his objective. It is important to note that this vector will form the internal representation of the world for a given agent and will depend on what the agent is capable of perceiving through his sensory system, of which the emotional state is also a part.

\section{Combat}

- Enemy Presence: indicates the presence of enemies in the environment.

- Enemy in sight: the agent has located at least one enemy within his range of vision.

- Danger zone: there is a large group of enemies in the vicinity.

- Close Shelter: there is a point in the vicinity where the agent can cover himself from enemy attacks.

\section{Objects}

- Replenish ammunition: there is ammunition at a close and known distance.

- Replenish power: here there is a power supply at a close and known distance.

Teammates

- Friend near: our teammate is at a close distance.

- SOS: your teammate has sent an SOS signal.

- Wounded teammate: your teammate is wounded and cannot continue fighting.

- Team Status: all team members have power and ammunition.

\section{Proprioception}

- Ammunition: quantity of ammunition you have.

- Power: quantity of power you have.

- Shelter: if you are sheltered from enemy attacks.

- Enemy Objective: enemy under attack, in the ongoing state.
- Enemies Killed: number of enemies eliminated in the course of the agent's persistence (time of existence in the system).

\subsection{Goals}

Goals or objectives, according to [36], are a description of the state of the environment that is desirable for the agent and are pursued actively through his actions $[6,10,12,13]$. In our case study, we have the following goals for our agents:

- Kill Enemies: Eliminate all enemies present in the environment by means of shots or blows.

o Environment vector: enemy presence $=0$

- Survive: keep a certain quantity of power during the existence of the game.

o Environment vector: power $>0$, Danger zone $=0$

- Protect Team: help teammates to kill enemies or pick them up when they are down (this happens when the variable that represents their health reaches zero due to attacks received from other agents).

o Environment vector: SOS $=0$, Wounded Teammate $=0$, Team Status $>0$

\subsection{Norms}

Before introducing our emotional model, we have to mention norms. Like goals or objectives that give an agent the motivation to perform a certain action or behavior, a norm allows the agent to establish a context in which actions could be respected or violated in a context of norms; that is, giving a punishment or reward for the action. That could be censurable or plausible [28]. For example, a soldier has a firmly established norm that tells him he must serve his country. If we observe the agent's actions, we can set a limit, which allows us to create a framework that tells us whether the agent is acting or not, according to the norms. In the case study, norms are important to evaluate certain emotions; hence, they are necessary for the proposed architecture. 
In the case study we propose just one norm on which our agents' actions will be judged.

As the authors of the OCC theory describe it to interpret whether a norm is observed or not, one needs to pay attention to the agents' actions through which one can interpret events that involve one or more agents. From this perspective, it is possible to interpret the observance of a norm. Thus, the norm will be formalized by the presence or absence of a set of events related to a specific agent $[6,12,13]$. In the case study, we define a single norm for our agents. This norm is defined below:

\section{Partners must help one another.}

Formed by the absence or presence, as the case may be, of the following events:

- Kill Enemy (agent-player). For the norm not to be violated, the event kill enemy performed by the agent-player must occur with regularity, in other words at least once every given interval of time $t_{E}$.

- Respond to SOS (agent-player). Like the preceding case, for the norm to be observed, an SOS must be answered by the agentplayer before a specified time $t_{A}$ has passed.

Friendly Attack (agent-player). In this case, the presence of the event in which the agent-player generates an attack to teammate will be sufficient cause to consider the norm violated. This can be seen as a direct

\subsection{Events}

Evaluation of events will allow us to establish a parameter on which emotions will be presented. As described in the preceding section, the Perception Module (PM) is a module in our architecture that is responsible for identifying these events and making them known to the agents that need to know about them. This obliges us to accurately define within the system the means of identifying these events. In the case study and based on the proposed emotions, we describe the meaning and characteristics of each of the events considered relevant to the agents depending on the context of the game.
Given that events are directly related to the representation of the environment and the changes it undergoes with the passing of time; we define the variables $t_{1}$ and $t_{2}$ as the initial and final moment in time, respectively, at which measurements are taken of the different variables of the representative vector.

\section{The events considered in the system are: Hope}

One definition of hope is when it is transferred to an object or person in whom you have confidence to get what you want. In the case study the event win is supported by the actions of the teammate.

Hope can be understood in the context of the situation in which the user's team has killed so many enemies that the value of the hope factor increases based on the possibility of emerging victorious due to the agent-player's leadership. This event occurs under the environmental conditions shown by 1 and 2 .

$$
E E A\left(t_{1}\right)+E E J\left(t_{1}\right)-E E A\left(t_{2}\right)+E E J\left(t_{2}\right)>F E
$$

$$
\text { and EEA }<
$$

where

- FE. Hope factor.

- EEA. Enemies killed by the agent in the totality of the game.

- EEJ. Enemies killed by the agent-player in the totality of the game.

\section{Enmity}

We assume that a situation of enmity occurs when an agent, despite sending an SOS, does not receive help from his teammate in a considerable time. This event is defined based on the properties of the environment. The environmental variables that indicate: a) a SOS, and b) a wounded teammate, appear simultaneously (1) for a time greater than TE (a given constant), in other words see Eqs. 3, 4 and 5

$$
\begin{aligned}
& \mathrm{SA}\left(\mathrm{t}_{1}\right) \text { and } \mathrm{CH}\left(\mathrm{t}_{1}\right)=1 \\
& \mathrm{SA}\left(\mathrm{t}_{2}\right) \text { and } \mathrm{CH}\left(\mathrm{t}_{2}\right)=1
\end{aligned}
$$




$$
\text { and } t_{2}-t_{1}>=T E
$$

where

- SA. SOS. CH. Wounded teammate.

- TE. Enmity Time (constant).

\section{Kill Enemy}

Occurs each time the agent-player kills an enemy. Shown by 6 .

$$
E E J\left(t_{1}\right)<E E J\left(t_{2}\right)
$$

where

- $\quad$ EEJ. Enemies killed by the agent-player in the totality of the game.

\section{Find Enemy}

Occurs each time an enemy appears in the agent's field of vision (FOV). Shown by Eqs. 7 and 8.

$$
\begin{aligned}
& \text { FOV }\left[\operatorname{EP}\left(t_{1}\right)\right]=0 \\
& \text { and } \operatorname{FOV}\left[\operatorname{EP}\left(t_{2}\right)\right]=1
\end{aligned}
$$

Where:

- FOV. Is the function that identifies when an enemy is in the agent's field of vision?

- EP. Enemy's position.

\section{Use Cover}

Generated each time a character is placed in the same position as a cover (1) for a specified time (a given constant). Eqs. 9, 10 and 11.

$$
\begin{aligned}
& \mathrm{UC}\left(\mathrm{t}_{1}\right)=1 \\
& \mathrm{UC}\left(\mathrm{t}_{2}\right)=1 \\
& \text { and } \mathrm{t}_{2}-\mathrm{t}_{1}<=\mathrm{TC}
\end{aligned}
$$

where

- UC. State in which the agent's position is at a distance near the position of the cover.
- TC. It is the minimum time to be under cover (a given constant).

\section{Pick Up Power}

Event generated on picking up the object that replenishes the characters' power supply. Shown by 12 .

$$
E A\left(t_{1}\right)<E A\left(t_{2}\right)
$$

where

- EA. Represents the agent's power at the given time.

\section{Pick Up Ammunition}

Generated on picking up the object that refills the character's ammunition. Shown by 13.

$$
\operatorname{MA}\left(\mathrm{t}_{1}\right)<\operatorname{MA}\left(\mathrm{t}_{2}\right)
$$

where

- $\quad$ MA. Represents the agent's ammunition at the given time.

\section{Find teammate}

It is an event that occurs when the user and his/her teammate are at a close distance for a given time. Shown by 14 .

$$
\text { DJA (t1)<DM; DJA (t2)<DM }
$$

where

- DJA. Distance calculated between the agent-player's current position and the agent accompanying him/her

- DM. Minimum distance established (a constant given).

Eliminate enemies near a teammate

Occurs when a given number of enemies near a teammate's position are eliminated. Shown by 15 and 16.

$$
\operatorname{EEJ}\left(\mathrm{t}_{1}\right)<\operatorname{EEJ}\left(\mathrm{t}_{2}\right)
$$




$$
\operatorname{DEEA}\left(\mathrm{t}_{2}\right)<\mathrm{DM}
$$

where

- EEJ. Enemies eliminated by the agentplayer in the totality of the game.

- DEEA. It is the distance between the position of enemies eliminated and the position of the agent accompanying the agent-player.

- $\quad \mathrm{DM}$. it is the minimum distance established (a constant given).

\section{Respond to SOS}

This event is generated after the events Find teammate and Eliminate enemies near teammate as long as the SOS signal is activated before they occur.

\section{Friendly Attack}

The event is generated when a projectile fired by the user collides with the agent that is the agentplayer's teammate (1). Shown by 17 and 18 .

$$
\begin{aligned}
& \mathrm{EA}\left(\mathrm{t}_{1}\right)>\mathrm{EA}\left(\mathrm{t}_{2}\right) \\
& \text { and Collision }\left[\mathrm{PDJ}\left(\mathrm{t}_{2}\right), \mathrm{PA}\left(\mathrm{t}_{2}\right)\right]=1
\end{aligned}
$$

where

- $\quad E A$. It is the power of agent.

- PDJ. Position of projectile fired.

- $\quad$ PA. It is the position of agent.

\subsection{Emotions}

An agent, in addition to perceiving the environment, also has the capacity to assess his own internal state (proprioception); thus, it is natural to extend this concept by implementing a model of emotions as one more characteristic of the agent's internal structure and by extension of the perception system. To achieve this, we identified the emotions we designed for our agent using an emotional assessment macrostructure, in other words a description of their origin, representation, and implications, so that they can be integrated in his behaviors. Each individual (in our case agent) is unique within our environment, and therefore perceives the world in a different form that drives to the feeling of different emotions. This implies different intensities because of his nontransferable dynamic emotional map that is represented in its emotional assessment macrostructure. Emotions will form a vector that will enrich the environment vector to produce a more complete representation of the world for the agent. When we attempt to incorporate emotions in our systems, it is important to take into consideration the problems they entail, even before a computational representation, some of which are discussed in greater detail in [28, 32]. Taking this into consideration and focusing on this project, each emotion we seek to use will be accompanied by a description and a set of characteristics that will allow the developer to present a clear idea of how the proposed emotion affects the agent and how it is being implemented in the system. In other words, it is necessary to understand the personality we seek to reproduce by relating emotions with behaviors. This is possible during the design process and it is based on the emotional assessment macrostructure developed (goals, norms, and objects). The elements necessary to describe an emotion are: a) name: it is a name to identify the emotion in the project. In some cases there is no suitable word in the language to identify a specific emotion; however, it is important to have a word, maybe in another language, or even an invented word, to identify it; b) psychological description: from a psychological perspective, there are many theories that seek to define and explain the function of emotions and their influence on human behavior. In the case study it is useful as a theoretical guide that helps identify its influence on the behavior and on which the implementation is developed; c) agent: given that the same emotion may be perceived differently by each agent, an emotional assessment macrostructure will be defined for each one using the concepts of the OCC theory. In other words, this concept tells us which agent in our system can experience the emotion described or is influenced by it; d) representation: a kind of representation refers to the implementation (logical, schematic, mathematical, etc.); e) parameters and variables: information about all kinds of parameters that may have a direct influence on the emotion. This aspect is intimately tied to the model specified in the psychological 
description, and it is according to the guide of design proposed by the OCC Theory; $f$ ) preconditions: specific characteristics or states of the system that are necessary to bring into existence or alter the representation of an emotion; g) consequences: it refers to the repercussions in different areas of the system when the emotion occurs.

Now we have a design template that will describe each of the emotions to be used in our case study. Taking into account the advice given by Ortony [2], who proposes that any project can start giving to the agents a couple of emotions (even only differentiating between positive and negative), and then broadening their emotional range using different techniques. In our case, we will propose giving our agent two emotions, which are described below. It is necessary to remark that each emotions must be linked to the parameters of the environment.

The Emotion of Contentment (pleased-disgusted) and Reproach (plausible- objectionable)

With the aid of the design template, the agent's behavior related to the first of the proposed emotions can be formalized.

\section{Name: CONTENTMENT}

- Psychological Description: defined by the OCC theory as being content due to a desirable event. It is classified among the emotions of consequences of the events.

- Agent: the agent that accompanies the agentplayer.

- Representation: represented by a level of intensity that takes values between 0 and 1 . The emotion is considered present when its intensity exceeds a predefined threshold.

- Parameters and Variables: threshold, intensity, and reduction factor, in other words the rate at which the variable's intensity diminishes.

- Preconditions: increase of intensity in response to the presence of events: Hope,
Use shelter, Kill enemy, Find enemy, Pick Up Ammunition, and Pick Up Power. The intensity value should be above the threshold.

- Consequences: specific consequences for behavior.

o Perception: his senses are more acute. He can see more distant objects.

o Decision making process: he reorganizes the predefined hierarchy of goals (1. To survive, 2. To protect team, 3. To kill enemies) taking into consideration the following order:
1. Killing enemies
2. Protecting team
3. Surviving

o Execution: his rate of motion increases. His power increases by a constant factor.

\section{- Consequences for other emotions:}

o The reduction factor for the emotion reproach increases.

On observing the behavioral consequences of the emotion contentment, we could conclude that our character becomes suicidal on experiencing that emotion because of the low priority assigned to the goal of surviving. However, it has another interpretation. When we speak of the usefulness emotions have for individuals, the argument is based on the question of how people try to make decisions that they will not have to regret later, and the process of choosing has a cognitive foundation which implies different perspectives from which an event can be interpreted [22]. In this case the role of norms is very important. For example, an individual in favor of saving whales can take certain actions against hunters, even at risk of her own personal safety. Such actions have as their objective to protect an ideal that, if compromised, can produce a very intense negative emotion. Thus, an agent who experiences the emotion of contentment in accordance with the design described above is not suicidal, he may be merely deciding that giving priority to his other goals, instead of his goal of survival is best for himself and for his beliefs (goals norms, and attitudes). The emotions are a hedonic experience; do what you think will make you feel better [22]. 
Name: REPROACH

- Psychological Description: Defined by the OCC theory as the capacity to approve or censure another person's action. It is considered an emotion of attribution in the group of emotions of the agents' actions.

- Agent: The agent who accompanies the agent-player.

- Representation: Represented by a level of intensity that takes values between 0 and 1 . The emotion is considered to be present when its intensity exceeds a predefined threshold.

- Parameters and Variables: threshold, intensity, and reduction factor, agent (human or character) toward whom reproach is felt.

- Preconditions: increase in intensity trough the absence of the events: Eliminate Enemy and Respond to SOS, and the presence of the event Friendly Attack. All performed by a teammate. The consequence is that the intensity value must be above the threshold.

- Consequences: specific consequences for behavior.

o Perception: none.

o Decision-making: He reorganizes the predefined hierarchy of goals (1. To survive, 2. To protect team, 3. To kill enemies) observing the following order:
1. Surviving
2. Killing enemies
3. Protecting team

o Execution: he sends no SOS signals and remains at a farther distance from the agent-player who is the object of the emotion.

\section{- Consequences for other emotions}

o The reduction factor for the emotion reproach increases.

\section{Emotional assessment macrostructure}

Our proposal uses a model of emotions that requires an appraisal system (cognitive theory of emotions), in other words, when dealing with emotions we know that they are present in each individual in different forms with varying intensity, which tells us that there is a process of evaluation, in which the stimuli and variables involved are evaluated. Consequently, there should be a means of relating the environment with emotions. In the case of goals they are norms, and for the objects they are the attitudes (the capacity of attraction) with each agent who experiences emotions in the system developed. Using a relational diagram, we have defined a structure called emotional assessment macrostructure to support the analysis and design of these complex relationships (Figure 3).

Although this structure is far from simple, it can be simplified for our purposes by developing a hierarchical structure in which the goals and subgoals involved are visualized. This hierarchy is dynamic as it considers events in the environment, and the environment in turn has dynamic characteristics. Given that goals are not pursued actively all the time, but each one has a degree of activation, this structure will allow us, through a hierarchy, to visualize the active goal at a given time and its importance for the individual.

Each node in the structure is related to a goal, the higher ranking nodes represent the most abstract or general goals while the lower ranking ones represent the most concrete and immediate goals. The nodes have input and output connections with other nodes. The input connections represent goals whose fulfillment may be affected by the fulfillment of lower level goals from which the link comes.

To interpret this emotional assessment macrostructure, we need to examine the different types of goals and possible links that can affect their relationships with the other nodes. In this classification we can find three types of goals:

Active Goals (A): these goals are those pursued actively with actions, which represent more general goals, those things that people would like to have done. 
Interest Goals (I): these goals, although existing for the individual, are usually related to things beyond his reach; in other words, they are goals that he/she would like to have fulfilled but can do nothing to further. A simple example is the goal of having a healthy family.

Filler Goals (R): these goals, similarly to active goals, have a unique characteristic: when they are fulfilled they do not disappear but reappear at a certain time or on certain occasions. Common examples of filler goals are eating, sleeping, reloading a gun in combat situation, etc.

The links between goals can be classified in the following types:

Necessary $(\mathrm{N})$ : these links indicate a need for the lower ranking goal to be fulfilled in order to aspire to the fulfillment of the higher ranking goal.

Sufficiency (S): in this case, when several goals are related to fulfill a higher goal, it will suffice for one of them to be fulfilled.

Facilitating $(F)$ : these links indicate the goals will facilitate the fulfillment of a higher goal, without their fulfillment being sufficient or necessary.

Inhibiting (I): the fulfillment of certain goals may cause the inhibition of others; in other words, given the context or its consequences, they do not permit the fulfillment of another goal.

Figure 3 shows our proposal for the agent who will accompany the agent-player during the game. We can see the principal goals the agent pursues marked with an $A$, in other words active goals. Similarly, we see a group of filler goals (marked with an R) that are related in different manners to the active goals.

Taking as our example the goal kill enemies, in our emotional assessment macrostructure we can see a link, marked with an $\mathrm{N}$, which indicates the need for the sub-goal kill enemy to be fulfilled before we can fulfill our higher ranking goal. Because there is more than one enemy in the environment, this subgoal must be fulfilled with regularity, which makes it a filler goal. Following the links we see the subgoal find enemy, which is necessary to fulfill the immediately higher goal. Clearly, these links help us to identify logic in the process, as it is evidently indispensable to find the enemy before taking any action to eliminate him. Continuing with our example, we observe the sub-goal use a cover, which is linked to other goals of different rank, where the $\mathrm{F}$ link tells us that if there is a chance of fulfilling that goal then it will facilitate our pursuit of the related goals.

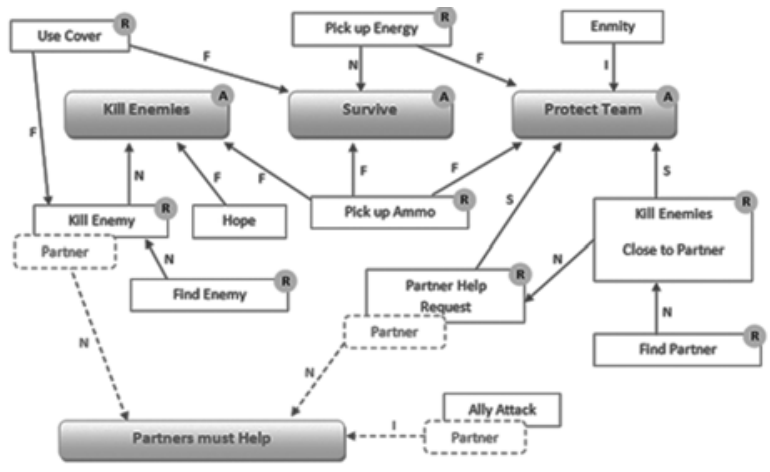

Figure 3. Emotional assessment macrostructure.

It is necessary to mention that each of the filler goals shown, has a related event (which in this project is identified with the same name); in other words, each time the filler goal pick up ammunition is fulfilled, a sign is produced that tells us that the agent has picked up from the environment an object that will give him more ammunition for his current weapon. This fact is of crucial importance as it allows us to include any event in our emotional assessment macrostructure that may occur in the environment. This offers us a context in which the agent is able to analyze events, identifying related goals and how they are affected. Returning to Figure 3, we find the event enmity, which can be interpreted as lack of help or communication from a teammate, something that clearly does not appear to be a goal and which, due to its type I link, tells us that the presence of that event inhibits the goal protect team; in other words, if we think that our teammate does not want to help us or does not send a message that he needs help, then it will be difficult to maintain the team's integrity.

The emotional assessment macrostructure also should include norms and attitudes, like those identified in the OCC theory [28]: 
Norms need to be included because they represent the beliefs in terms of which moral and other kinds of judgmental evaluations are made, and attitudes (including tastes) need to be included because they constitute the basis for the appraisals of appealingness which are the foundation of liking.

Given this point, there is no impediment to include the norms, which we have defined previously in Section 4.3, and availing ourselves of the same tools to relate it with goals and/or events. Thus, our emotional assessment macrostructure is enriched, as shown in Figure 3.

With this emotional assessment macrostructure, we can identify norms and their links with dotted lines. In the case study the specified norm is called partners must help one another. We see that it has three related events, two of them marked with an $N$, which we interpret as a necessary one; in other words it is required for these events to occur to satisfy the norm; on the other hand, the event friendly attack has an inhibiting link, which tells us that it should not occur if we want the norm to be present. Finally, we identify another element, enclosed in a rectangle with dotted lines. This element indicates the agent responsible for the action described by the related event, in the case of the event friendly attack, this element tells us that the agent's teammate attacked his/her own teammate which, as we have mentioned, means that the norm has been breached.

From this point, we have a scheme that allows us to find a relationship between the agent's goals and norms together with all occurrences present in the environment interpreted as events or, if applicable, as an action-agent pairing. These relationships allow us to make an evaluation based on the levels of variables of desirability, plausibility, etc., for each emotion. This in turn allows us to obtain a level of intensity useful to define the presence or absence of each particular emotion. The totality of the evaluation process takes place in the Affective Individual Module (AIM) grouping and presenting the necessary information on emotions that another system module of the emotive architecture may require (see Figure 2).
In conclusion, our proposal postulates a cycle of interaction, shown in Figure 4, which can be summarized as follows:

Agents who make an evaluation based on desirability or higher ranking goal interpret events produced in the environment which produces increases in the intensity of the emotion. If this occurs, it causes a reorganization of the hierarchy of goals, and consequently a review of the current behavior. Behavior translates into actions that affect the environment producing changes that will eventually produce an event.

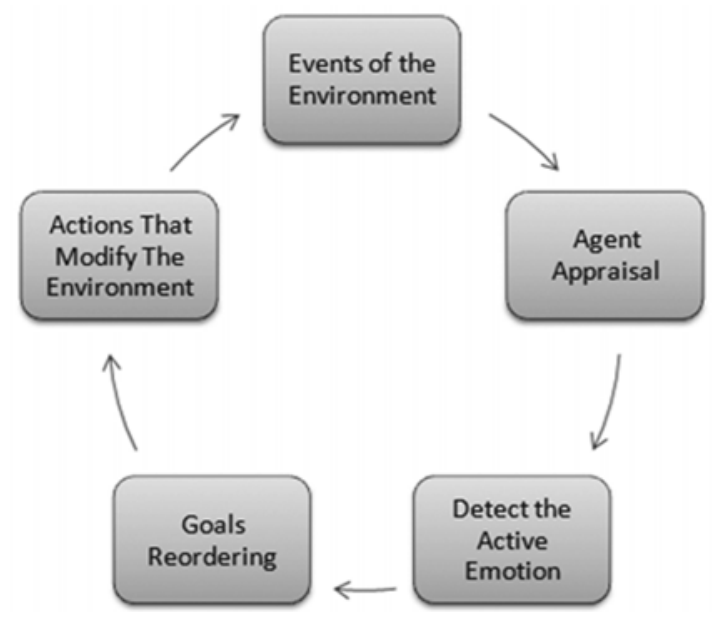

Figure 4. Cycle of emotive architecture.

\section{Identifying the emotional model}

Bearing in mind the purpose for which this application was created, this section verified the functioning of the emotional model and how it affects the agents' behavior in the different situations that arise.

Like adjusting parameters of game difficulty, the emotional model also requires a set of data that must be provided for the emotive entities involved. In our case, those variables will affect only the character. Their configuration may be a means of specifying certain types of personality.

For each emotion the character can experience, it is necessary to specify: 
- Threshold. Below-threshold values will indicate that the character is prone to experience the related emotion. On the other hand, in an emotion such as contentment, if the threshold is very high, the character will be susceptible to the emotion, which could be interpreted as a pessimistic disposition; in this case the character is rarely happy with a situation.

- Reduction factor. Indicating the rate at which the related emotion will diminish over time. A low reduction factor in an emotion such as reproach may indicate that a character maintains his emotional condition for a long time, which could represent a resentful personality that does not easily forget negative events.

The perception module may consider some other parameters, to establish specific conditions on each of the events detected. However, in the case of our implementation, it suggests a restriction beyond which we should have reservations regarding a change of this kind, as it could not only affect the system's performance but it can also introduce an added difficulty when we attempt to introduce other emotive entities in the environment.

Establishing values related to the affective architecture, we make a series of observations in order to validate the functioning of the affective system. Below, we present the behaviors observed for each of the active emotions.

\subsection{Emotionless state}

An emotive entity can be a neutral emotional state; in other words, a state in which he has no emotion, which means that the intensity has not exceeded the threshold in any of the possible emotions. Such a case is considered a cognitive state where decisions are usually based on the priority given to each of the predefined goals (default values).

The design performed assigns an order to the higher priority goals. In a neutral emotional state, the agent will attack the enemy as long as his energy is at an acceptable level and his partner does not need help. This is the situation found at the start of the game.
The agent's goal changes if his teammate needs help. This situation is depicted in Figure 5, where the goal has changed to healing a wounded partner (From time (1) to time (2)).

Figure 5 shows:

- Think: Active

- Protect_Team: Active Goal

- Heal_Partner: Active Goal (after the SOS call). The first character

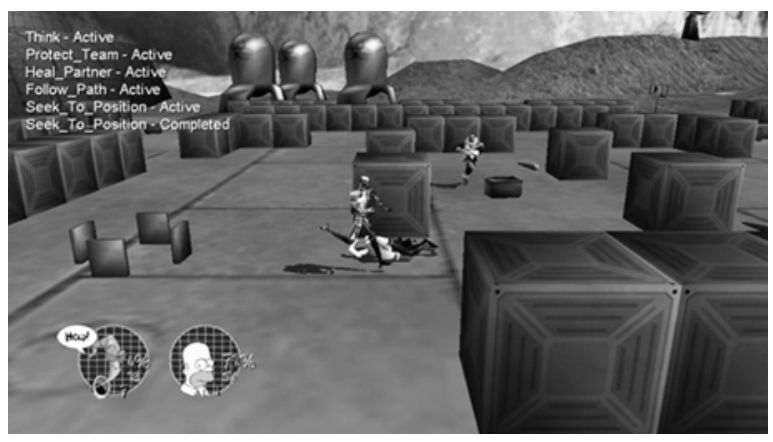

Figure 5. No active emotion. Goal of protecting the team.

In another situation, given that survival is the highest priority goal, Figure 6 shows how in a low energy state, the plan generated leads the agent to search for an item, completely ignoring the fact that his partner is wounded and asking him for help.

- Think: Active

- Survive: Active Goal

- Get Item: Active Goal

- Heal_Partner: Active Goal (after the SoS call). The first character does not have energy

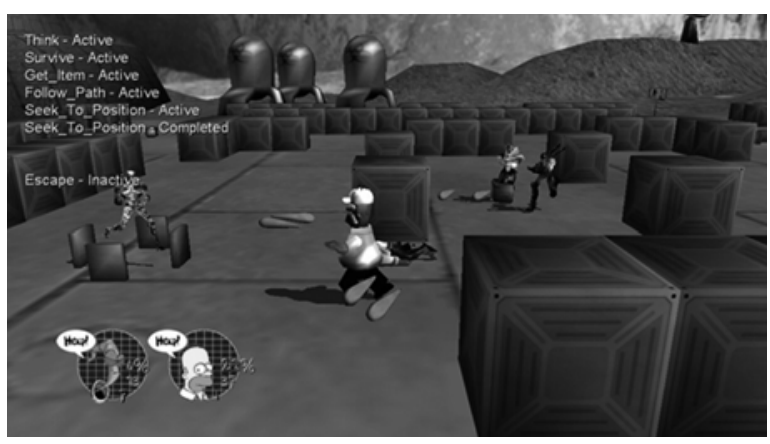

Figure 6. No active emotion. Goal of survival. 


\subsubsection{Emotion of contentment}

Different events have occurred in the environment and now our character experiences an emotion of happiness, defined in our design as the emotion of Contentment.

His expression is clear, and so are his intentions. Figure 7 shows how, although his condition is not the best because he has run out of ammunition, his plan is to protect his team, and because his partner is not requesting his help, he can get ammunition that improves the team's overall condition.

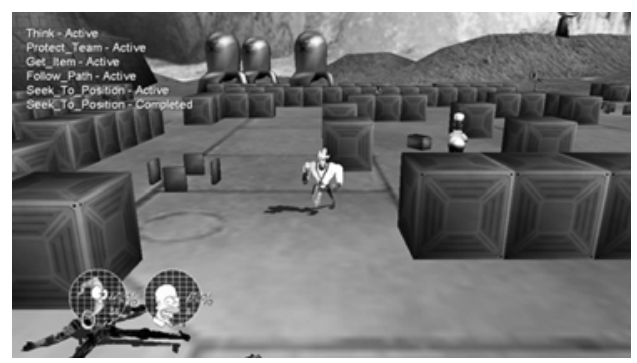

Figure 7. Contentment Emotion. The character is happy to protect his team.

- Think: Active

- Protect Team: Active Goal

- Get_Item: Active Goal

- Follow_Path: Active Goal. The first character

The character's emotional state has caused him to ignore his own survival, preferring to attack the enemy, which can be seen in Figure 8, as after recovering his ammunition (Figure 7 ), he changes his plan to attack, ignoring that his condition is not the best.

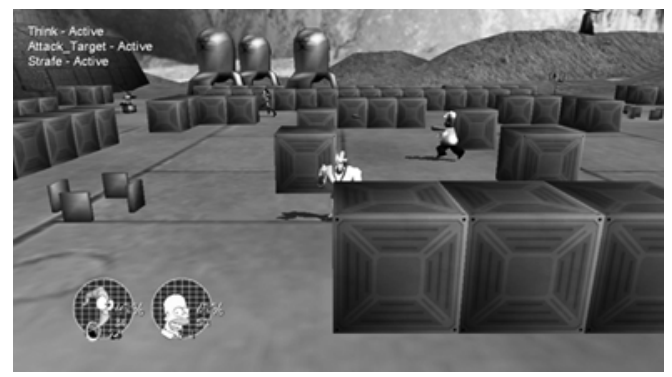

Figure 8. Emotion of Contentment causes the character to risk his energy.
- Think: Active

- Attack Target: Active Goal

- Strafe: Active Goal. The first character

\subsubsection{Emotion of reproach}

Finally, we analyze one of the situations in which the emotion present is that which we define as reproach. Experiencing an emotion of attribution that indicates that one of the defined norms has been violated. In this case, we assume a situation where the emotive entity has been altered remaining inactive; even though an SOS has been sent, help has not arrived promptly. Figure 9 shows how after the established time, the agentplayer decides to help his partner, who immediately shows his current emotion and embarks on a plan to get an energy item due to his weakened internal state.

- Think: Active

- Survive: Active Goal

- Get_Item: Active Goal. The second character

Meanwhile the agent-player is attacked by nearby enemies, which weakens his state. Analyzing his options, the user requests the aid of his partner who is now in better condition due to the energy item he has just obtained. However, the emotion of reproach toward his partner is still present which causes a change in the hierarchy of goals, giving priority to his survival.

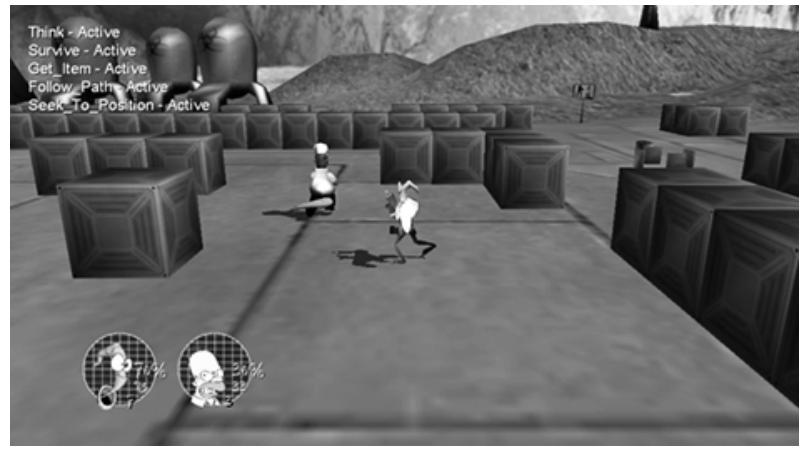

Figure 9. Emotion of disdain at not receiving help sooner.

Figure 10 shows how the plan made by the affective character corresponds to getting another 
item to improve his chances, completely ignoring the SOS sent earlier. This behavior continues even after the agent-player is defeated, leaving him with no other choice than to wait for the emotion of reproach to diminish over time. Finally, when that occurs, if his partner is able to help him, he will do so too.

- Think: Active

- Survive: Active Goal

- Follow_Path: Active Goal. Second character

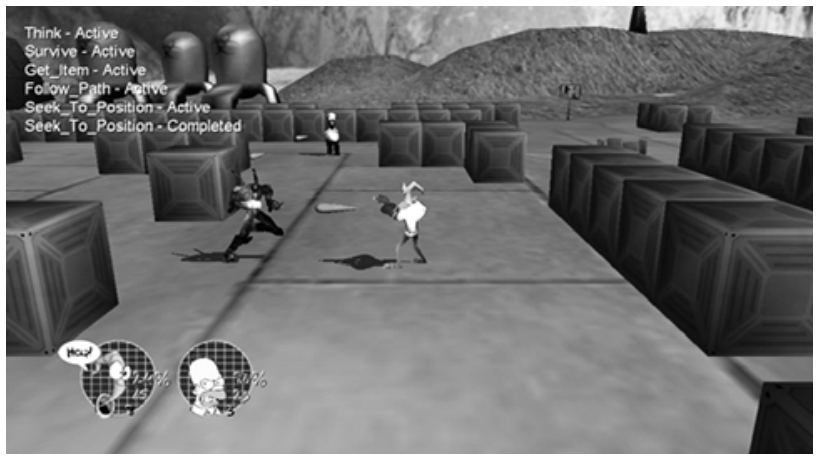

Figure 10. Emotion of constant disdain. Note that the character's energy is at $80 \%$ and even so his goal is to survive at all costs

\section{Conclusions}

This paper shows how including emotions can enrich a behavior. The case study is situated in the generic architecture of a videogame [29], where a cognitive module is attached that is capable of taking emotions into consideration in order to produce a given action. To this end, an emotive architecture is designed based on the OCC theory. It is our understanding that the mechanism proposed in this is not the same that produces a physical mechanism in the body and plays a significant part in producing human feelings. However, we propose a means of quantifying emotions, associated with the characters of a videogame. The model presented describes variables and procedures that are useful in synthesizing emotions.

The first objective defined in this project was related to the enrichment of the behavior of autonomous agents in virtual environments. This idea proposed the use of the OCC theory, which seeks to explain how emotions originate in the cognitive processes of individuals. The theories and investigations analyzed show the influence of the affective elements on human behavior, specifically on the decision-making process. These ideas were the foundation for the hypothesis that the behavior of autonomous agents would be enriched with a cognitive structure of emotions to be implemented in the context of a videogame architecture, which represents one of the most relevant contributions.

In the context of this project, we considered the type of agents that inhabit videogames, which are related to a set of events and objectives established by the videogame. Because the principal actor is the user, a naturally emotional individual, this contribution seeks to enhance her relationship with the autonomous agents present by creating emerging behaviors, which have their origin in the emotions experienced by the agent. Those emotions will be predefined by the design of the videogame and activated by interaction with the environment, the user, and the pursuit of objectives.

To include emotions in the agents' behavior, we established the primary objective of creating an emotional assessment macrostructure, which had to satisfy certain basic aspects related to the characteristics of the systems that make up a videogame.

The design of the game was affected with the sole aim of incorporating key elements, both in the final behavior of the agents and in the recognition of certain necessary conditions in the environment. This stage offered an analysis of characters, enriched by the exploration of both their goals and the behaviors, all of which are affected by different emotions. These were defined formally to avoid many of the problems of ambiguity that often arise in the interpretation of emotions. In the case study, the evaluation starts from the fact that the agent behaves coherently with the information received from the two sources considered in the decision-making process: 1) the internal source (emotions) and 2) the external source (environment). 


\subsection{Future work}

We believe that the formalization of emotions still requires refinement to define clearly its dynamics and function with other aspects of the agent. The suggested reorganization of the hierarchy of goals is seen as an unchangeable fact in each of the emotions. While it is inevitable to indicate certain aspects of this organization, we expect the existence of a better technique to make this process more flexible. Allowing, based on a set of parameters, to justify this change to runtime. This idea could bring agents a dynamic goal system which evolves over time goals by adopting new and discarding others.

Another aspect to consider is the reference to the personality of each agent. Although this is a phenomenon that succeeded to simulate many different ways, for example with parameter variation, an extension of our architecture could pose a personality module that influences aspects such as the tendency to experience certain set of emotions; however, its contribution is more prominent by adding an extra stage to the decision-making process. In the event that an agent presents an emotion at a particular time, such as sadness, a personality module can help to formalize a plan of action. In other words, if we consider that an agent has a depressive personality, sadness can cause you to lose most of its active goals, producing an inactivity behavior. Conversely, if the agent has a sunny personality, an emotion of sadness can become a motivation to take an action plan to eliminate the cause of the affective state, even ignoring existing goals.

Memory is one of the variables to be considered for an extension of the model. Its use as memories can help create affective tendencies in the characters regarding events occurred. At an early stage, this effect may gradually alter the thresholds specified for each emotion, which will also offer a new way to create a changing personality in the characters. Gradually, this emotional memory could also create changes in functions that determine the degree of impact on the valuation of each event, making the agent susceptible to certain environmental events that were previously ignored. 


\section{Acknowledgments}

This paper is part of the research undertaken by David A. Acevedo-Moreno to obtain the Master of Engineering in Computer Science Degree at Postgrado en Ciencias e Ingeniería de la Computación UNAM. It was supported by CONACYT grant 1548 and it was also part of the divisional project Soft Computing and Applications funded by Universidad Autónoma Metropolitana.

\section{References}

[1] D. A. Acevedo-Moreno et al., "Design of an Emotive Architecture for Videogames", Memorias en CD, ISBN 978-970-15-14388-2, En el XXI Congreso Nacional and VII Congreso Internacional de Informatica y Computacion de la ANIEI, Monterrey, 2008, pp 99-106.

[2] D. A. Acevedo-Moreno, "Diseño de una Arquitectura para Incorporar Emociones en un Videojuego". MSc. Degree Thesis. Posgrado en Ciencia e Ingeniería de la Computación-UNAM, 2009, Available from http://ce.azc.uam.mx/profesores/clc/

[3] D. A. Acevedo-Moreno, "Diseño de una Arquitectura para Incorporar Emociones en un Videojuego", Ciencia, Tecnología e Innovación para el Desarrollo de México. Section Tesis de Posgrado: A40011-DF-2009-MT. Latindex ISSN: 2007-1310, 2011. Available from: http://pcti.mx.

[4] C. Becker et al., "Connecting Feelings and Thoughts - Modeling the Interaction of Emotion and Cognition in Embodied Agents", Proceedings of the Seventh International Conference on Cognitive Modeling (ICCM06), Trieste: Edizioni Goliardiche 2006, pp. 32-37

[5] R. Brooks, "Intelligence Without Representation", Artificial Intelligence, Vol. 47, pp. 139-159, 1991

[6] M. d'Inverno and M. Luck,. "Understanding Agent Systems". Berlin, Germany: Springer Verlag. Second edition. 2010, pp. 257

[7] D. Goleman, "La inteligencia emocional", México: Eds B México para Javier Vergara Ed., 2000, pp. 397.

[8] J. Gratch and S. Marsella, "A domain-independent framework for modeling emotion", Cognitive Systems Research, Vol. 5, pp. 269-306, 2004

[9] A. Laureano-Cruces, "Interacción Dinámica en Sistemas de Enseñanza Inteligentes", Tesis de Doctorado en Investigación Biomédica Básica, Instituto de Investigación Biomédica, UNAM, 2000. Available from http://ce.azc.uam.mx/profesores/clc/.
[10] A. Laureano-Cruces and F. de Arriaga-Gómez, "Reactive Agent Design For Intelligent Tutoring Systems", Cybernetics and Systems, Vol. 31, No. 1, pp. 1-47, 2000.

[11] A. Laureano-Cruces et al., "Cognitive task analysis: a proposal to model reactive behaviors". Journal of Experimental \& Theoretical Artificial Intelligence, vol. 13, pp. 227-239, 2001.

[12] A. L. Laureano-Cruces and A. Barcelo-Aspeitia, "Formal Verification of Multi-Agent System Behaviour Emerging from Cognitive Task Analysis", Experimental \& Theoretical Artificial Intelligence, Vol. 15, No. 4, pp. 407413, 2003.

[13] A. L. Laureano-Cruces and G. Espinosa-Paredes, "Behavioral Design to Model a Reactive of an Expert in Geothermal Wells", International Journal of Aproximate Reasoning, Elsevier, Vol. 39, No.1 pp, 1-28, 2005.

[14] A. L. Laureano-Cruces et al, "Hacia Interfaces Inteligentes", en Libro Científico: Avances de las Mujeres en las Ciencias, las Humanidades y todas las disciplinas. Sustentabilidad, Aire, Agua, Fuego y Tierra, ISBN: 978607-477-212-8, México: CYAD/UAM-A, 2009, pp. 237-246.

[15] A. L. Laureano-Cruces et al., "Emotions as an Element that Maximizes the Effectiveness of a Pedagogical Agent", In T. Bastiaens et al. (Eds.), Proceedings of World Conference on E-Learning in Corporate, Government, Healthcare, and Higher Education 2009, Chesapeake, VA: AACE, ISBN: 1880094-76-2, 2009, pp. 2817-2822.

[16] Laureano-Cruces et al., "Implementation of an affective-motivational architecture tied to a teachinglearning process", In J. Sanchez \& K. Zhang (Eds.), Proceedings of World Conference on E-Learning in Corporate, Government, Healthcare, and Higher Education 2010, Chesapeake, VA: AACE, ISBN: 1880094-53-5, 2010, pp. 1930-1938.

[17] A. L. Laureano-Cruces and D. O. Verduga-Palencia, "Simulación de un juego de futbol utilizando una arquitectura Multiagente-Reactiva", en memorias del XXIII Congreso Nacional y XI Congreso Internacional de Informática y Computación de la ANIEI, ISBN: 978-607-707-097-9, Desarrollo Tecnológico, Alfa-Omega, 2010, pp. 485-493.

[18] A. L. Laureano-Cruces and A. Rodríguez-García, "Design and implementation of an educational virtual pet using the OCC theory", Journal of Ambient Intelligence and Humanized Computing. DOI 10.1007/s12652-0110089-4, Vol. 3, No. 1, pp. 61-71, 2012.

[19] A. L. Laureano-Cruces et al., "A Cognitive Model for the Red Baron: a Perspective Taking into Account Emotions", ICGST-Artificial Intelligence Machine Learning Journal, ISSN: 1687-4846 Print, ISSN: 16874854 Online. Vol. 11, Issue 2, pp. 5-13, 2011. 
[20] A. L. Laureano-Cruces and E. Hegmann-Gonzalez, "Maze Videogame that Adapts to the User's Emotions According to his Behavior", ICGST-Artificial Intelligence Machine Learning Journal, ISSN: 1687-4846 Print, 16874854 Online, Vol. 11, Issue 2, pp. 21-25, 2011.

[21] A. L. Laureano-Cruces et al., "Operative Strategies Related to an Affective Motivational Architecture to Achieve Instructional Objectives", ICGST-Artificial Intelligence Machine Learning Journal, ISSN: 1687-4846 Print, ISSN: 1687-4854 Online, Vol. 11, Issue 2, pp. 15-20, 2011.

[22] G. Loewenstein, and J. S. Lerner, "The role of affect in decision making". En R. J. Davidson et al., (Eds), Handbook of Affective Sciences, Oxford, New York: Oxford University Press, 2003, pp. 619-642

[23] M. Minsky, "The Emotion Machine: Commonsense Thinking, Artificial Intelligence, and the Future of the Human Mind", New York: Ed. Simon \& Schuster, 2006, pp. 387.

[24] R. Morris et al., "Cognitive Systems: Information Processing Meets Brain Science", London, U. K.: Elsevier Academic Press, 2006, pp. 310.

[25] M. Mora-Torres et al., "Estructura de las Emociones dentro de un Proceso de Enseñanza-Aprendizaje", Perfiles Educativos (UNAM), ISSN: 0185-2698, Vol. XXXIII, núm. 131, pp 64-79, 2011.

[26] E. T. Mueller and M. G. Dyer, "Daydreaming in humans and computers", Proceedings of the Ninth International Joint Conference on Artificial Intelligence, Los Angeles, CA, 1985, pp. 278-280.

[27] H. S. Nwana, "Software agents: An overview", The knowledge Engineering Review. Vol. 11, No.3, pp. 205-244. 1996

[28] A. Ortony et al., "The cognitive structure of emotions", ISBN: 978-052-13-8664-7, Cambridge, UK: Cambridge University Press, 1988, pp. 207.

[29] R. Parent, "Computer Animation. Algorithms and Techniques", Berkeley, CA: Morgan Kaufman Publishers, ISBN: 978-155-86-0579-4, 2002, pp. 529.

[30] P. Petta and R. Trappl, "Emotions and Agents", in Multi-agents systems and applications, New York, NY: Springer-Verlag New Tork, Inc., ISBN: 3-540-42312-5, 2001, pp. 301-316.

[31] P. Petta and R. Trappl, "Why to Create Personalities for Synthetic Actors". In P. Petta and R. Trappl (eds.), Creating Personalities for Synthetic Actors: Towards Autonomous Personality Agents, ISBN: 3-540-62735-9, London, UK: Springer-Verlag, 1997, pp. 1-8.
[32] R. W. Picard, "Affective Computing", Cambridge Boston: MIT Press, Second Printing, 1998,

[33] T. Ramírez-González, "Algoritmo de Planificación Distribuido en un Sistema de Control Basado en una Arquitectura Multiagente en Tiempo Real", MSc. Degree Thesis. Universidad Autónoma MetropolitanaAzcapotzalco (MCC). 2006. Available from http://ce.azc.uam.mx/profesores/clc/

[34] T. Ramírez-González, "Algoritmo de planificación en un sistema de control distribuido basado en una arquitectrua mult-agente". En Ciencia, Tecnología e Inovación para el desarrollo de México. Sección Tesis de Posgrado en México: A4-0012-DF-2007-MT. ISSN Latindex: 20017-1310, 2011. Available from http://www.pcti.mx/.

[35] J. Reeve, "Understanding Motivation and Emotion", $5^{\text {th }}$ edition. Hoboken, N. J.: John Wiley \& Sons, 2009, pp. 600.

[36] S. Russel and P. Norving, "Artificial Intelligence: A Moderm Aproach", 3rd. Edition, Upper Saddler River, NJ: Prentice Hall of Pearson Education, 2009, pp. 1152.

[37] H. A. Simon, "Motivational and emotional controls of cognition", Psychological Review, vol. 74, pp. 29-39, 1967.

[38] B. Scott, "The Illusion of Intelligence", in S. Rabin (ed), Al Game Programming Wisdom, ISBN: 978-15845-0077-3, Charles River Media, 2002, pp. 16-20. 